\title{
Fifty years of publishing in biomedical engineering: reflections after 7-year editorship
}

\author{
Jos A. E. Spaan - Ruben Coronel
}

Received: 11 November 2012/ Accepted: 13 November 2012

(C) International Federation for Medical and Biological Engineering 2012

The 50th volume of Medical and Biological Engineering and Computing, MBEC, comes to its end. This is a rather long history and $M B E C$ is one of the oldest journals in the field. It is therefore of interest to see how the journal has developed over the years.

MBEC started out in 1963 as a quarterly journal and also under a different name, Medical, Electronic and Biological Engineering. In 1966, it became bimonthly and only in 2006 it changed to a monthly publication. Over the last 40 years, the number of papers per issue has remained rather steady. Yet, competition had increased. From 1997 to 2011, the number of journals in the category Engineering-Biomedical raised from 41 to 72 . In addition, many journals in physiology and medicine now feature engineering and technological sections.

The number of submitted and accepted papers over the last 15 years elicits some fluctuations but is rather stable between, 120 and 140 per year, whereas the number of submissions has increased sharply from 300 to 700 since 2005, the year in which the now-departing editors started with the responsibility for the publications from January 2006 onward. However, the change of editor was not the only parameter variation that occurred at that time. The journal changed to Springer as new publisher and with this the submissions to the journal became fully web based.

The growing difference between submitted and accepted manuscripts indicates a strong increase in rejection rates over the last 15 years and the doubling of it in the last 6 years. The policy of the journal with respect to accepting papers has not changed over these periods. Reviewers are

J. A. E. Spaan $(\bowtie) \cdot$ R. Coronel

Academic Medical Center, University of Amsterdam,

Amsterdam, The Netherlands

e-mail: j.a.spaanl@amc.uva.nl asked to grade the manuscripts numerically between 1 and 100. Manuscripts with a score over 75 for the first submission usually make it to acceptance and between 65 and 75 acceptance depends strongly on the quality of revision. There is no strict policy not to grow and, therefore, one has to conclude that the increase in submissions is due to the decrease in quality of the manuscripts. Authors apparently submit their materials very early at an immature stage. This certainly has to do with the increasing pressure on all of us to publish. We wish to add some critical notes in this respect.

Bibliometric indices have been developed to assess the impact of papers, journals and whole research fields on the scientific and clinical community. Obviously, these indices are of interest as measurement of impact of topic under evaluation but when applied to give a quality judgment of researcher or journal it is easy to oversimplify. For example, the Hirsh factor, h-factor, is used to rank scientists for their impact. It reflects the number of papers, $N$, that has more than $N$ citations. Nobel prize winners in physics have h-factors between 60 and 110 and leading authors in life sciences may reach over 190. These differences cannot be interpreted as a substitute for the IQ of these scientists nor can these be seen as equivalent to the impact of them on society at large. It is simply impossible to quantify the difference of impact of technology and science behind the GPS system and the human genome. One thing is certain, the impact of the human genome would be much less without the innovations made in technology underlying the sequencing and analysis of DNA.

The differences in $\mathrm{h}$-factor for scientists have a lot to do with the characteristics of publishing and citing in different fields, as has nicely been analyzed in our journal by Opthof [23]. These differences are in general not taken into account when it comes to evaluation of performance of 
biomedical engineers [29]. It is difficult to say what the $\mathrm{h}$-factor is for a good biomedical engineer. Gefen [13] has attempted to establish some realistic values by analyzing the h-factors of all professors in biomechanics at departments of biomedical and bio-engineering at the top ten universities in the US as defined by the US Center for Measuring University Performance. ${ }^{1}$ The same was done for 21 European universities on the 200 World Universities in the ranking list of Times Higher education magazine. The h-factor was 32 for the US biomechanical engineers and 20 for the European ones. Gefen indicates that additional studies are needed to explain the US-European difference but one of the factors he mentioned is the overall greater activity in cellular and tissue engineering in the US, which is cited by a broader research community such as biologists and biochemists.

We will use a personal example to illustrate the dependency of citations on the nature of the work that is published. It concerns research on the endothelial glycocalyx performed in the group of the first author based on animal research and later translated to clinical research within the Department of Internal Medicine at the same university hospital. We looked for the best-cited basic research paper on the glycocalyx which appeared in Circulation in 2000 [34] and the best-cited clinical research paper published in Diabetes in 2006 [22]. Over the period of 6 years after publication, the basic paper was cited 55 times and the clinical paper 109 times, a factor of two difference. It is clear that the clinical paper would not have been published without the basic research that was, nevertheless, less cited. The difference cannot be attributed to the difference in quality of the journals published in, since the impact factor of Circulation is about twice as high as Diabetes. The observation of more frequent citations for clinical studies versus basic studies also holds within the same journal [23]. The difference is likely explained by the larger group of researchers involved in clinical than in basic research. Notwithstanding these imperfections of the $\mathrm{h}$-factor, it remains to play a dubious role in the assessment of individual researchers [30]. The growth of the personal h-factor is considered a measure of scientific quality and has become a direct impetus for submission of incomplete research data.

Notwithstanding limitations of bibliometric indices, these are of interest in measuring the performance of a journal especially within a group of journals in the same scientific field. Important indices are the 2- and 5-year impact factors, IF. In the last 6 years, the 2 -year IF for $M B E C$ increased from just below 1 to 1.878 . Based on these numbers, one may conclude that the profile of the journal in the community has increased over the last

\footnotetext{
${ }^{1}$ http://mup.asu.edu/research2008.pdfS.
}

7 years. When the now-departing editors started, $M B E C$ was in the lowest quartile in the Biomedical Engineering group but now we are in the top half. Importantly, the cited half-life, which is defined as the median age in years of the items in the journal cited in a certain year remained high and decreased only a little from 10 to 9.6 . This number is at the very top of the biomedical engineering journals but is also high compared to many high-ranking medical journals. Hence, papers published in $M B E C$ are cited for a long time. The increase in quality of the journal is not only the result of the voluntary work of the editorial team but most of all the result of the work of thousands of reviewers who were willing to give their advice without remuneration also. We thank our reviewers for this exceptional willingness to share their ideas and improve the work of their colleagues.

Besides what these numbers tell us, it is important what our authors think of our journal. Springer did a survey under authors and they were asked to rate several properties of the journal on a scale from 1 to 5 with 1 as the strongest value. The best-rated properties were Reputation (1.4), International Scope (1.5) and Quality of Review (1.5). These are ratings the journal may be proud of.

$M B E C$ has a strong traditional engineering character and maintained that over the years. The papers the editors like most are those which combine theoretical analysis with experimental or clinical work. Another important aspect by which the manuscripts are judged is the degree of innovation and the level of validation and also on thoroughness of the analysis. Hence, one may find in $M B E C$ papers with a strong theoretical background such as the computation of the potential field [33], development of atrial fibrillation [10] and development of modeling framework for patientspecific computational hemodynamics [1]. This is not to say that a study on comparison of methods or instruments cannot make it into MBEC. However, this depends on the estimated impact that the study may have on the clinical community such as with the noninvasive measurement of arterial blood pressure [36].

We have tried to analyze whether there is a shift in scientific focus of $M B E C$ over the years. For this, we looked first at the ten best-cited papers from 1975 onwards ${ }^{2}$ in slots of 5 year. In each time slot, the h-factor of the journal was about 33 except for the last two due to the reduced time available for citation. In the earlier time slot, between 30 and $50 \%$ of the papers deal with the heart and circulation another 20 percent with the neural system or analysis of the EMG. The other top-cited papers deal with instrumentation and a variety of other techniques. Obviously the nature of the studies evolved over time and now includes image processing, tissue engineering, nanotechnology and patient-specific modeling. To give some insight

\footnotetext{
${ }^{2}$ No papers from before 1975 could be found in Web of Science.
} 
onto the best-cited original papers, we selected the top ten from the periods 2008-2009 and 2010-2011. Out of these 20 papers, 7 are in the area of the circulation $[8,9,15,20$, $24,25,27], 7$ in the area of rehabilitation including brain computer interface $[6,7,11,14,16,17,28], 2$ related to sleep [19, 35], 2 to tissue engineering and nanotechnology and 2 to electroporation [4, 21]. Obviously the distribution of these subjects of publications are somewhat influenced by the special issues we had over this period $[2,5,12,18$, 26, 31, 32].

A matter of concern is the standard of ethics in the community [3]. We require that all experiments on humans and animals have been approved by the appropriate ethical committees, that human experimentation conforms to the declaration of Helsinki, and that human subject are informed and agree in writing. These requirements are not always met, and this results in the immediate rejection of the manuscript. The editors plead for ethical guidelines that can be applied internationally to the entire engineering community. Another concern is the poor presentation skills of authors from countries with emerging scientific activities. The community will need to support these authors and develop a system of mentorship.

Our conclusion is that the nature of the journal has not changed over time and that its quality and visibility has improved. $M B E C$ covers a broad spectrum and notwithstanding the growth of specialized journals in many areas of biomedical engineering; we remain strong in several of these areas. We are also proud to be a platform for emerging fields for which such specialized journals do not exist. In the end, $M B E C$ is the journal of the International Federation of Medical and Biological Engineering and has to serve this community of biomedical engineers in all its aspects worldwide.

\section{References}

1. Antiga L, Piccinelli M, Botti L, Ene-Iordache B, Remuzzi A, Steinman DA (2008) An image-based modeling framework for patient-specific computational hemodynamics. Med Biol Eng Comput 46:1097-1112

2. Avolio A, Westerhof BE, Siebes M, Tyberg JV (2009) Arterial hemodynamics and wave analysis in the frequency and time domains: an evaluation of the paradigms. Med Biol Eng Comput 47:107-110

3. Coronel R, Spaan JA, Voigt HF (2011) Engineering and ethical constraints. Med Biol Eng Comput 49:1-2

4. Corovic S, Zupanic A, Kranjc S, Al Sakere B, Leroy-Willig A, Mir LM, Miklavcic D (2010) The influence of skeletal muscle anisotropy on electroporation: in vivo study and numerical modeling. Med Biol Eng Comput 48:637-648

5. Cutti AG, Veeger HE (2009) Shoulder biomechanics: today's consensus and tomorrow's perspectives. Med Biol Eng Comput 47:463-466
6. Cutti AG, Giovanardi A, Rocchi L, Davalli A, Sacchetti R (2008) Ambulatory measurement of shoulder and elbow kinematics through inertial and magnetic sensors. Med Biol Eng Comput 46:169-178

7. Cutti AG, Ferrari A, Garofalo P, Raggi M, Cappello A, Ferrari A (2010) 'Outwalk': a protocol for clinical gait analysis based on inertial and magnetic sensors. Med Biol Eng Comput 48:17-25

8. De Santis G, Mortier P, De Beule M, Segers P, Verdonck P, Verhegghe B (2010) Patient-specific computational fluid dynamics: structured mesh generation from coronary angiography. Med Biol Eng Comput 48:371-380

9. Dobbe JG, Streekstra GJ, Atasever B, van Zijderveld R, Ince C (2008) Measurement of functional microcirculatory geometry and velocity distributions using automated image analysis. Med Biol Eng Comput 46:659-670

10. Dossel O, Krueger MW, Weber FM, Wilhelms M, Seemann G (2012) Computational modeling of the human atrial anatomy and electrophysiology. Med Biol Eng Comput 50:773-799

11. Ferrari A, Cutti AG, Garofalo P, Raggi M, Heijboer M, Cappello A, Davalli A (2010) First in vivo assessment of "outwalk": a novel protocol for clinical gait analysis based on inertial and magnetic sensors. Med Biol Eng Comput 48:1-15

12. Garcia N, Sabater-Navarro JM, Gugliemeli E, Casals A (2011) Trends in rehabilitation robotics. Med Biol Eng Comput 49:1089-1091

13. Gefen A (2011) How high is a "high" hirsch index in biomechanics research? J Biomech 44:206-208 (Discussion 208-209)

14. Greene BR, McGrath D, O'Neill R, O'Donovan KJ, Burns A, Caulfield B (2010) An adaptive gyroscope-based algorithm for temporal gait analysis. Med Biol Eng Comput 48:1251-1260

15. Hagblad J, Lindberg LG, Andersson AK, Bergstrand S, Lindgren M, Ek AC, Folke M, Linden M (2010) A technique based on laser Doppler flowmetry and photoplethysmography for simultaneously monitoring blood flow at different tissue depths. Med Biol Eng Comput 48:415-422

16. Horki P, Solis-Escalante T, Neuper C, Muller-Putz G (2011) Combined motor imagery and SSVEP based BCI control of a 2 dof artificial upper limb. Med Biol Eng Comput 49:567-577

17. Lau HY, Tong KY, Zhu H (2008) Support vector machine for classification of walking conditions using miniature kinematic sensors. Med Biol Eng Comput 46:563-573

18. Lim CT, Han J, Guck J, Espinosa H (2010) Micro and nanotechnology for biological and biomedical applications. Med Biol Eng Comput 48:941-943

19. Mendez MO, Bianchi AM, Montano N, Patruno V, Gil E, Mantaras C, Aiolfi S, Cerutti S (2008) On arousal from sleep: time-frequency analysis. Med Biol Eng Comput 46:341-351

20. Mulvany MJ (2008) Small artery remodelling in hypertension: causes, consequences and therapeutic implications. Med Biol Eng Comput 46:461-467

21. Napotnik TB, Rebersek M, Kotnik T, Lebrasseur E, Cabodevila G, Miklavcic D (2010) Electropermeabilization of endocytotic vesicles in b16 f1 mouse melanoma cells. Med Biol Eng Comput 48:407-413

22. Nieuwdorp M, van Haeften TW, Gouverneur MC, Mooij HL, van Lieshout MH, Levi M, Meijers JC, Holleman F, Hoekstra JB, Vink H, Kastelein JJ, Stroes ES (2006) Loss of endothelial glycocalyx during acute hyperglycemia coincides with endothelial dysfunction and coagulation activation in vivo. Diabetes 55:480-486

23. Opthof T (2011) Differences in citation frequency of clinical and basic science papers in cardiovascular research. Med Biol Eng Comput 49:613-621

24. Orini M, Bailon R, Enk R, Koelsch S, Mainardi L, Laguna P (2010) A method for continuously assessing the autonomic 
response to music-induced emotions through hrv analysis. Med Biol Eng Comput 48:423-433

25. Parker KH (2009) An introduction to wave intensity analysis. Med Biol Eng Comput 47:175-188

26. Pries AR, Mulvany MJ, Bakker EN (2008) MBEC special issue on microcirculation "engineering principles of vascular networks". Med Biol Eng Comput 46:407-409

27. Reneman RS, Hoeks AP (2008) Wall shear stress as measured in vivo: consequences for the design of the arterial system. Med Biol Eng Comput 46:499-507

28. Schepers HM, Roetenberg D, Veltink PH (2010) Ambulatory human motion tracking by fusion of inertial and magnetic sensing with adaptive actuation. Med Biol Eng Comput 48:27-37

29. Spaan JA (2009) Biomedical engineering and bibliometric indices for scientific quality. Med Biol Eng Comput 47:1219-1220

30. Spaan JA (2010) Arrogance and ignorance in assessing scientific quality in a multidisciplinary academic medical centre. Neth Heart J Mon J Neth Soc Cardiol Neth Heart Found 18:319-322
31. Stride E, Edirisinghe M (2009) Special issue on microbubbles: from contrast enhancement to cancer therapy. Med Biol Eng Comput 47:809-811

32. Supek S, Magjarevic R (2011) Neurodynamic measures of functional connectivity and cognition. Med Biol Eng Comput 49:507-509

33. van Oosterom A (2012) Closed-form analytical expressions for the potential fields generated by triangular monolayers with linearly distributed source strength. Med Biol Eng Comput 50:1-9

34. Vink H, Constantinescu AA, Spaan JA (2000) Oxidized lipoproteins degrade the endothelial surface layer: implications for platelet-endothelial cell adhesion. Circulation 101:1500-1502

35. Xiong G, Zhan J, Zuo K, Li J, Rong L, Xu G (2008) Numerical flow simulation in the post-endoscopic sinus surgery nasal cavity. Med Biol Eng Comput 46:1161-1167

36. Zheng D, Amoore JN, Mieke S, Murray A (2011) Estimation of mean arterial pressure from the oscillometric cuff pressure: comparison of different techniques. Med Biol Eng Comput 49:33-39 